\title{
The Dynamics of Thefts and Robberies in São Paulo's Metro, Brazil
}

\section{Vania Ceccato ${ }^{1} \cdot$ Gustavo Moreira $^{2}$ (D)}

Published online: 25 August 2020

(C) The Author(s) 2020

\begin{abstract}
The aim of this study is to assess the nature and space-temporal dynamics of property crimes (theft and robbery) in transport nodes, namely, metro stations and their immediate surrounding areas. The analysis is based on crime data over São Paulo's metro system from 2010 to 2017. Drawing from environmental criminology theory, the methodology combines geographical information system (GIS) as well as statistical analysis using hypothesis testing and negative binomial regression models. Results show that thefts happen more often inside the station and robberies outside, with signs of possible interaction between these environments. Crime is often highly concentrated in a few inner city and end stations, but it varies depending on location and time. Future research and policy implications of the results add to the contribution of this current study.
\end{abstract}

Keywords Property crimes $\cdot$ Transit crime $\cdot$ Routine activity $\cdot$ GIS $\cdot$ Binomial regression models

\section{Introduction}

The aim of this study is to assess the nature and space-temporal dynamics of theft and robbery in metro stations and their immediate surrounding areas. This is an important topic because transit crime is not only a serious problem for public transportation operators all around the world (e.g. Shellow et al. 1974; Levine and Wachs 1986; Smith and Clarke 2000; LoukaitouSideris et al. 2002; Newton et al. 2014; Shibata et al. 2015) but also has a major individual, socio-economic and environmental impact on our societies. If travellers are at risk while in

Vania Ceccato

vania.ceccato@abe.kth.se

Gustavo Moreira

gustavocmoreira@ufsj.edu.br

1 Department of Urban Planning and Built Environment, KTH Royal Institute of Technology, Stockholm, Sweden

2 Department of Economics, Federal University of São João del Rei, São João del Rei, Brazil 
transit (or at least feel so), they may take private transportation options or suffer impaired mobility (Natarajan 2016; d'Arbois and Vanier 2017; Ceccato and Loukaitou-Sideris 2020). Transit safety is doubtlessly a fundamental issue with reference to social sustainability (UNUnited Nations-Habitat 2018). This study is also important because it contributes to the increasing literature on transit crime and, in particular, a better understanding of the nature of metro stations as criminogenic places and as 'risky places' (Block and Davis 1996; Block and Block 1999, 2000) or 'risky facilities' (Clarke and Eck 2007).

We make use of crime records covering 8 years of the metro system in São Paulo, Brazil. The São Paulo metro system is located in one of the world's biggest cities; the system is also one of the most crowded, with more than four million individuals travelling every business day in 67 stations in a city of 12 million inhabitants. While most studies in the international literature focus on North American or European metro systems (e.g. Loukaitou-Sideris et al. 2002; Newton et al. 2015; Ceccato et al. 2013), this article illustrates the temporal and spatial dynamics of crimes at station level in a big city of the Global South. This might add to the evidence that can contribute to test the applicability of criminological theories beyond cities of the Global North that are embedded in different contexts from the ones in the Global South, where levels of deprivation and lack of social control may generate differences in patterns and levels of crime in transit environments. These differences are relevant when defining crime prevention strategies in public transport (for India, see Mazeika and Kumar 2017). São Paulo is also well known as a city with high inequality levels, where many people are considered 'transit captive', which may affect victimization.

Metro stations have a fixed location in space; they are linked to human activities, at particular times that are regulated by a rhythmic schedule of trains, and bound to generate many crime opportunities. For instance, Brantingham et al. (1991, p. 93) suggest that 'transit shapes crime patterns of the city by moving large proportions of high-risk populations around the city along a limited number of paths and depositing them at a limited number of destinations'. Such regularity, we argue, can be explored by safety experts to understand what happens in the stations and their immediate surroundings but also in areas far beyond these nodes. Official statistical data (traffic flow, crime events during peak and off-peak hours) can serve as 'benchmarks' for the entire city, broken down by peak and off-peak hours or inside and outside a station.

The aim of this study is to contribute to the international literature by investigating the nature and space-temporal dynamics of theft and robbery in São Paulo's metro stations and their immediate surrounding areas. The aim is achieved by:

(i) Comparing the time trend (hourly and daily) of crime inside and outside the stations

(ii) Analysing the spatial dynamics of crime inside and outside the stations and the extent of spatial concentration at city and station level

(iii) Using binomial regression models to model theft and robbery levels in the station in relation to those found in surrounding areas, controlling for land use and demographic and socio-economic factors in the immediate vicinity

We focus on thefts and robberies because they constitute the majority of crimes recorded by the police in these transport nodes. This study builds on two previous analyses on the São Paulo metro system (Ceccato and Paz 2017, and Moreira and Ceccato 2020) that focused on violence. In addition, the temporal and spatial dimensions of crime inside and outside the stations - an issue neglected in the previous studies - is examined. This analysis of metro stations is made possible because we can differentiate between crimes that happen in the 
internal and external environments of the stations. As suggested by Brantingham et al. (1991), public transport travel paths are defined (and entrances to these paths are restricted), even more so in the case of a closed system such as the metro, which makes it easier to test potential differences in the levels of crime internally and externally.

The structure of this article is as follows. 'Theoretical Background on Transit Crime' section explains why it is important to assess transport nodes as a criminogenic place, and then it explores the potential association between crimes that occur inside and outside the stations in a temporal and spatial perspective. Hypotheses are also stated in 'Theoretical Background on Transit Crime' section, followed by the presentation of the study area, data sources and methods in 'Framing the Case Study' section. In 'Results' section, the results are reported, and in 'Discussion of the Results' section, the results are discussed in relation to the current literature. Finally, the conclusions are presented with some implications for research, policy and practice in 'Conclusions and Recommendations' section.

\section{Theoretical Background on Transit Crime}

\section{Metro Stations and Their Environments as Criminogenic Places}

Metro stations are criminogenic places (Thrasher and Schnell 1974; Belanger 1999), but they are not equally dangerous in time and space (La Vigne 1997; Loukaitou-Sideris et al. 2002; Loukaitou-Sideris 2011; Ceccato et al. 2013; Piza and Kennedy 2013; Newton et al. 2014, 2015; Irvin-Erickson and La Vigne 2015). Crimes in metro stations are not limited by their opening hours, also taking place when stations are not operating (Ceccato and Uittenbogaard 2014), a fact that has also been observed for other risky facilities (Brantingham and Brantingham 1995, Vandeviver et al. 2019).

Some metro stations pull motivated offenders towards them; in others, crime opportunities are a result of the flow of passengers that varies over time. A station's platform can provide the necessary conditions for pickpocketing (e.g. Ceccato et al. 2013), while the entrances provide the anonymity required for open drug scenes (see, e.g. Magnusson, 2020). Yet, not all platforms or entrances are defined by the same environmental characteristics. The environmental design of a metro station and its auxiliary sections, such as entrances and exits, influence surveillance and may affect opportunities for crime (Myhre and Rosso 1996; La Vigne 1997; Irvin-Erickson and La Vigne 2015; Ceccato 2018; Loukaitou-Sideris et al. 2002). What happens at the stations depends not only on their physical environments, but also on the human activities that take place at these transportation nodes when travellers are on the move. Piza and Kennedy (2013) described, for instance, how both easy entrance and exit from stations, as well as passengers' lack of familiarity with metro stations, lead to increased opportunity for offenders to commit crimes.

Physical and socio-economic characteristics found in the surrounding areas of a metro station may also draw the attention of potential offenders, in particular if other risky facilities, such as schools, convenience stores and parking lots, are located in the area. Metro stations are often considered to be crime generators, where a large number of people are attracted to an environment and a portion ends up committing criminal activities. Alternatively stations can also be defined as crime attractors, where intending criminal offenders are attracted due to well-known opportunities for crime (Brantingham and Brantingham 1993, 1995). Yet, the distribution of crimes in these 'risky places' (Block and Davis 1996; Block and Block 1999, 
2000) or 'risky facilities' (Clarke and Eck 2007) is not well understood, in particular in relation to the potential interactions between stations' internal environments and the context in which they are embedded. This complexity will be discussed in more detail below.

\section{The Temporal Patterns of Crime in Metro Stations}

Crime opportunities are neither uniformly nor randomly distributed in space and time (Ratcliffe 2010), but they do follow rhythmic patterns of human activity, some varying daily, others weekly or seasonally. Temporal variations of crime are related to people's routine activity. According to Cohen and Felson (1979), most crimes depend on the convergence of potential offenders, targets and capable guardians. The temporal distribution of crimes both inside and outside stations is expected to follow these principles.

The international literature points to a direct relationship between theft and overcrowding (Smith and Clarke 2000; Ceccato et al. 2013), but these overcrowding conditions vary by day of the week, inside and outside the stations. Peak hours are expected to promote more thefts inside the stations than in regular times. On the other hand, a temporal association has been found between crime in these transit environments and the low flow of passengers and therefore less natural surveillance, which generate conditions more disposed to robbery (Smith and Clarke 2000; Burrell 2007). Newton et al. (2014) found that crimes inside and outside London Underground stations were positively correlated throughout the hours of the day, with the exception of inter-peak (10:00-15:59) and late night time periods (22:00-01:59). Studies that investigated possible temporal associations of crime inside and outside metro stations found that the crime rates inside and outside Washington metro stations were not correlated over the years (La Vigne 1996, 1997).

\section{The Spatial Patterns of Crime in Metro Stations}

As for the spatial distribution of crime, central stations, often located in central areas, constitute the core of the daily convergence of travellers, and they become a locus of crime. Although stations are characterized as hotspots of crime, previous research showed that crime is not distributed equally among them (Smith and Clarke 2000; Loukaitou-Sideris et al. 2002; Newton 2004; Newton and Bowers 2007), partly because of the internal environment of the stations. There are features capable of affecting the risk of victimization, such as police surveillance (La Vigne 1997), CCTV (Webb and Laycock 1992; Ceccato et al. 2013; Priks 2015) and the design of the metro itself (La Vigne 1996; Newton et al. 2014; Uittenbogaard and Ceccato 2015).

However, a station's external characteristics, such as the socio-economic conditions of the resident population, can also influence the occurrence of crimes that occur within them. Becker (1968) suggests that economically rich areas attract criminals, given the possibilities of greater return from illegal activity (more crime opportunities). In turn, economically vulnerable areas are often associated with weak social control, which also leads to criminality according to the theory of social disorganization (Shaw and McKay 1942; Kornhauser 1978; Bursik and Webb 1982). Yet, environmental criminology theory has evolved in the last century to show that the mechanisms linking disadvantage and offending are much more complex than the mere expected link between poverty and crime (for a review, see Ceccato 2017). For instance, areas with high stocks of social capital are more effective in exerting informal social control through the establishment and maintenance of norms (Hirschfield and Bowers 1997; Rosenfeld et al. 2001). Yet, Sampson et al. (1997) showed that strong local social ties or associations are not 
enough to generate mechanisms of social control that help prevent crime. People only exercise social control when they share values and are willing to intervene on behalf of the common good, the mechanism known as collective efficacy. In problematic areas, if metro stations are embedded in areas with multiple signs of downward spiral and 'weakening of the norms governing behaviour' (Sampson et al. 1997, p. 41), then more crime is expected both inside and outside the stations.

The environments inside and outside the stations are not spatially independent, and the literature has pointed out that criminogenic stations are surrounded by areas with a higher level of crime (for an exception, see La Vigne 1996). Ceccato et al. (2013) found that high levels of crime at stations are often related to high levels of crime in the surrounding neighbourhoods. Irvin-Erickson and La Vigne (2015) also highlighted that stations located in economically vulnerable and criminogenic areas are those with the highest risk of crime. Newton et al. (2014) also noted an association between pickpocketing in and out of stations for the London Underground. The mechanisms linking crime to metro stations also include differences in land use and socio-economic factors (Loukaitou-Sideris et al. 2002; Cozens et al. 2003; LoukaitouSideris 2011; Ceccato et al. 2013; and Newton et al. 2014). In general, these authors found an impact of population composition (density, demography, income levels) and land use factors (e.g. presence of ATM, commerce) on crime at stations.

\section{Hypothesis}

Three main hypotheses were tested in this study. The first hypothesis is that thefts and robberies show distinct temporal patterns of occurrence and such a variation is not uniform inside and outside stations. While 'thefts need a crowd to take place' (Felson 2013, in Ceccato et al. 2015) and thus often happen during peak hours (when the station is crowded), robbery instead demands anonymity, taking place more often during off-peak hours, when stations' environments are uncrowded.

The second hypothesis refers to the spatial concentration of property crimes. Thefts and robberies are concentrated in stations embedded in the inner city, where more people converge daily and there are more crime opportunities because many other 'risky places' and 'risky facilities' are concentrated there (Clarke and Eck 2007).

The third hypothesis relies on the concept of transit stations as criminogenic places that either generate or attract crime (Brantingham and Brantingham 1993, 1995). It is expected that after controlling for internal characteristics of the metro stations as well as those found in their surroundings (land use and socio-economic characteristics), levels of crime in the station would be affected by the levels of offences that happen around the stations.

\section{Framing the Case Study}

\section{The Study Area}

With about 12 million inhabitants, São Paulo municipality is the largest city in Brazil and in South America. Taking into account the metropolitan area with 39 neighbouring municipalities, the total population reaches 21 million inhabitants, about $10 \%$ of Brazil's population. According to the Mobility Survey (Metro 2012), there are around 44 million daily trips in the Metropolitan region of São Paulo, of which $68 \%$ are performed by motorized vehicles. The 
municipality is served by public transportation: buses, metro lines and commuting trains. The metro is composed of six lines with 67 stations and is 83.3-km long (Fig. 4). In 2018, almost four million individuals travelled by metro every business day (Metro 2019). The busiest line is the Red line, which links the inner city to the eastern districts of the municipality (PalmeirasBarra Funda $\leftrightarrow$ Corinthians-Itaquera), serving an average of one million users daily with 18 stations. The busiest station is the central one, Sé, that links the Blue and Red lines, with an average flow of passengers of 500 thousand people per day. The study area includes 65 stations, excluding two new stations that belong to the new line (Grey line).

Previous research shows that thefts and robberies (and total crimes) are more prevalent in stations in São Paulo located in inner city areas but also in smaller stations and in relatively wealthier neighbourhoods (Ceccato and Paz 2017). Violence is also highly concentrated in space, with more than $40 \%$ of the violent encounters occurring in stations situated within $2 \mathrm{~km}$ of the central station; this is true especially for female victims, while men are at higher risk of suffering violence at a metro line's end station (Moreira and Ceccato 2020). Links between crimes and neighbourhood characteristics extend beyond transportation nodes and vary spatially and temporally (Ceccato 2005, Ceccato et al. 2007). Moreira and Ceccato (2020) also found that there was more violence in metro stations located in economically disadvantaged peripheral neighbourhoods than in the rest of the municipality.

\section{Data Acquisition and Preparation}

The research is based on three data sources. Police recorded crime obtained from the Public Security Secretary of São Paulo (SSP-SP) for 1 January 2010-31 January 2017 constitutes one dataset. This includes all offences registered with the Police in São Paulo, with 2.4 million observations, the information including crime type, its location (by $\mathrm{x}, \mathrm{y}$ coordinates) and the declared time of the offence.

The first step was to identify whether the crime occurred within a station. For this purpose, the geographical coordinates of each metro station (from GeoSampa portal) were used. From January 2010 to January 2017, 11,297 thefts and robberies were classified as occurrences within a metro station. In order to be considered a crime that happened inside the station:

i The geographical coordinates of the crime should be the same as that of the metro.

ii The description of the location (string variable) should indicate that the crime occurred at a station.

Figure 1 provides the distribution of the number of thefts and robberies across metro stations in São Paulo.

The second step was to determine what would be considered the 'surroundings' or the 'immediate area' around the metro station. In this study, a radius of $150 \mathrm{~m}$ from the station was considered. This radius was chosen because $150 \mathrm{~m}$ covers the extensions of the stations, including all entrances/exits.

Two other sources of data were employed in this study: land use around the stations, from the Metropolitan Train Company (CPTM), and the demographic and socio-economic data by census tract from 2010 around the stations. The average number of users for each metro station was used for modelling purposes measuring the level of thefts and robberies per users in each station, as well as the number of CCTVs, both provided by Metropolitan Train CompanyCPTM - which administers the São Paulo metro. Within a radius of $150 \mathrm{~m}$ around each of the 


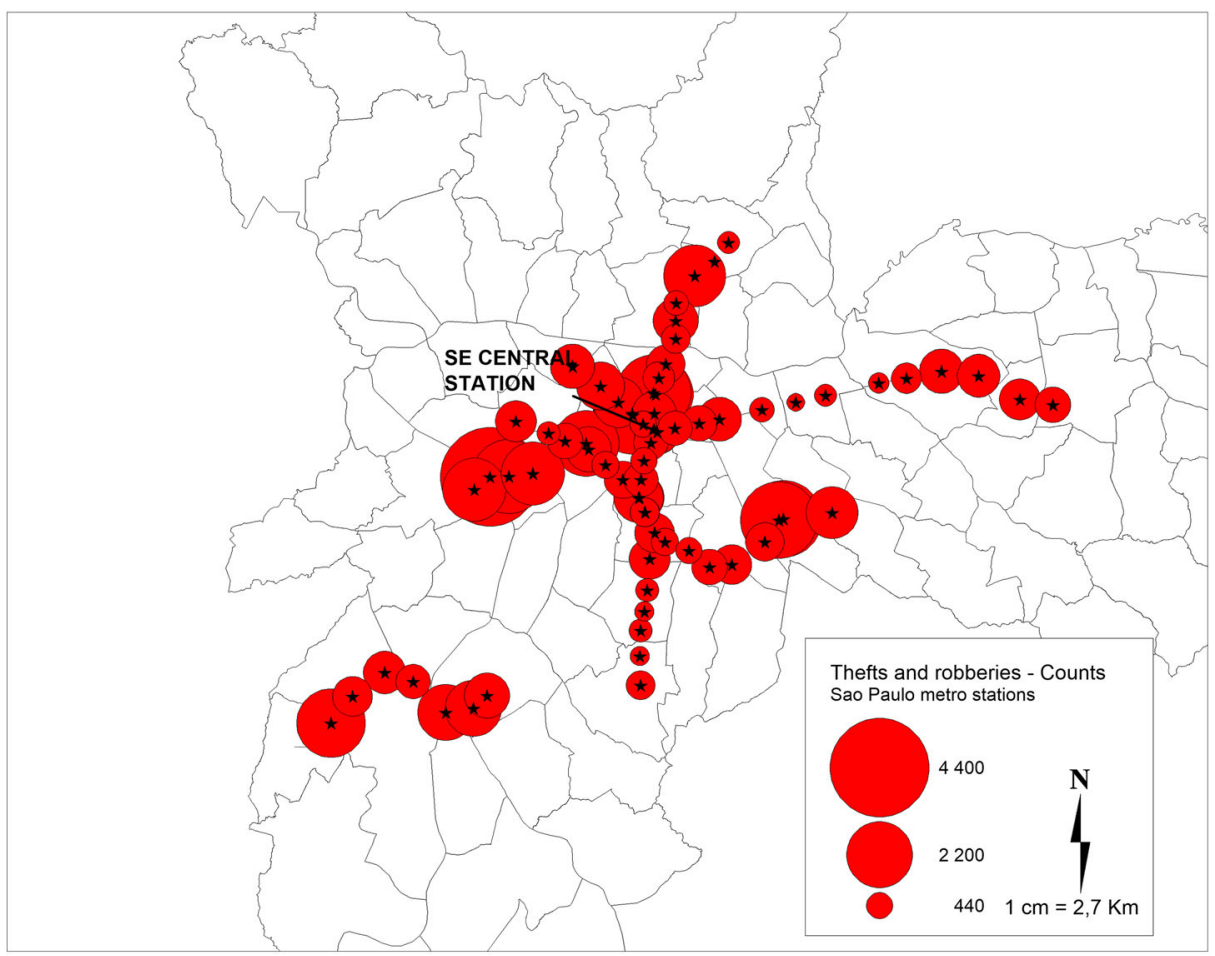

Fig. 1 Distribution of thefts and robberies across metro stations in São Paulo, 2010-2017

stations, the presence of commercial areas, schools, squares, parking lots and bus stops was identified by using Google street view images as Ceccato and Paz (2017) and Moreira and Ceccato (2020). Finally, data from the 2010 Demographic Census were used, obtaining socioeconomic information from the region for the season, such as the average per capita income of the population and the number of resident men aged 20-29 years old. For modelling, a combination of land use characteristics and demographic/socio-economic data was used as independent variables (Appendix Table 4).

\section{Temporal Analysis}

In order to verify the temporal variations between the crime that occurs inside and outside São Paulo metro stations, graphic analysis was used to represent the percentage distribution of crimes over the hours and days of the week. After visual inspection, tests of proportion hypotheses ( $z$ test) are applied to verify whether or not there is a temporal association between the proportion of crimes that were recorded in these two environments. For this test, we followed Felson and Poulsen (2003) measuring crime quartiles throughout the time of day with days starting at 5 a.m., and the classification used for the time division of the days was 1 st quartile (05:00-11:59), 2nd quartile (12:00-16:59), 3rd quartile (17:00-20:59) and 4th quartile (21:00-04:59). As for the daily analysis, the proportion of crimes that occur between weekdays and weekends was compared. 


\section{Spatial Analysis}

As for the analysis of the spatial association between crimes that occur inside and outside the stations, a visual analysis was performed using the estimation of a Kernel density function. This technique consists of a smoothed and non-parametric analysis of events, in this case transit crimes (for more details, see Greene 2003, p. 881). Following procedures similar to those found in the transit literature (Ceccato et al. 2013; Ceccato and Paz 2017; Moreira and Ceccato 2020), the central station (Sé station) was used as reference, since it is the most crowded station with more than 500,000 users per business day and it is located in the core of the city of São Paulo. In addition to the visual inspection of the results of the Kernel density function, the two-sample Kolmogorov-Smirnov test was applied to test whether the distribution of crimes inside the station was statistically significant and different from outside. The analysis was complemented by the inclusion of a covariate representing the level of off-season crimes in the empirical modelling, which is described below.

\section{Modelling}

Negative binomial models were estimated using the maximum likelihood method (for details on this methodology, see Cameron and Trivedi 2005; Greene 2003; and Hilbe 2011) in order to explain the variability of crimes (thefts and robberies) by station. This type of model is more appropriate to analyse aggregate crime rates because of the nature of counting data, resolving empirical problems related to least-squares analysis (e.g. Osgood 2000). The use of this methodological approach was also motivated by the fact that crime data follows the 'law of rare events' characterized in Cameron and Trivedi (2001) and, thus, are naturally skewed right, i.e. there are many cases of few or zero crime count and few cases of high crime count.

The selection of these variables was based on previous literature on transit crime, environmental criminology and the conceptual model of proposed by Ceccato (2013) that was previously applied in metro systems in Sweden and Brazil (Ceccato 2018). The model states that crime is influenced by a range of environmental characteristics related to the (1) characteristics of the station itself but also (2) the environment where the station is embedded within each neighbourhood and (3) in the particular city context. The selection of the variables used in this study (covariates showed in Table 1) follows this conceptual model, namely:

1 The characteristics of the station (CCTV, Endstation, Transitionstation)

2 Land use around the station (Green area, Parking lot, Bus stops, Commercial areas, schools); level of crime around the station (Crimearound); and socio-economic characteristics (Income, Young men)

3 Location of the station in the city (Centralstation).

The individual covariates were pre-selected before modelling. First, an analysis of correlation between all covariates identified variables that would potentially contribute with similar information to the models. Since the explanatory variables were not highly correlated (the highest was $R=0.6$ ), all the chosen variables were kept (Table 4). Table 1 describes the variables employed in the empirical model, the source of collection and some descriptive statistics. Note that as the socio-economic characteristics (per capita income and young men) were only available for the year 2010, the incidence of robberies and thefts was compiled by 
Table 1 Variables used in the empirical model to explain the observed variability of crimes in São Paulo's metro stations

\begin{tabular}{|c|c|c|c|c|c|}
\hline Variable & Description & Mean & s.d. & Min & Max \\
\hline CCTV & Number of security cameras inside each station & 28.94 & 12.33 & 14 & 76 \\
\hline Endstation & 1 if the station is an end station, otherwise 0 & 0.1 & 0.3 & 0 & 1 \\
\hline Transitionstation & 1 if the station has a connection to other lines, otherwise 0 & 0.11 & 0.32 & 0 & 1 \\
\hline Centralstation & 1 if the station is the central station (Sé station), otherwise 0 & 0.06 & 0.23 & 0 & 1 \\
\hline Crimearound & $\begin{array}{l}\text { Number of thefts and robberies recorded within } 150 \mathrm{~m} \text { of the } \\
\text { station, per } 100,000 \text { residents }\end{array}$ & 29.18 & 37.01 & 2.25 & 260.21 \\
\hline Green area & $\begin{array}{l}1 \text { if there are parks within a radius of } 150 \mathrm{~m} \text { from the station, } \\
\text { otherwise } 0\end{array}$ & 0.34 & 0.47 & 0 & 1 \\
\hline Parking lot & $\begin{array}{l}1 \text { if there are parking lots within } 150 \mathrm{~m} \text { of the station, } \\
\text { otherwise } 0\end{array}$ & 0.61 & 0.49 & 0 & 1 \\
\hline Bus stops & 1 if there is a connection with bus stops, otherwise 0 & 0.41 & 0.49 & 0 & 1 \\
\hline Commercial & $\begin{array}{l}1 \text { if there are commercial areas within } 150 \mathrm{~m} \text { of the station, } \\
\text { otherwise } 0\end{array}$ & 0.89 & 0.32 & 0 & 1 \\
\hline Schools & $\begin{array}{l}1 \text { if there are schools within a radius of } 150 \mathrm{~m} \text { from the } \\
\text { station, otherwise } 0\end{array}$ & 0.23 & 0.42 & 0 & 1 \\
\hline Income & $\begin{array}{l}\text { Average per capita income of residents around the station (in } \\
\text { Brazilian Real) }\end{array}$ & 2540 & 1688.7 & 393 & 6044 \\
\hline Young men & $\begin{array}{l}\text { Number of young males ( } 20-29 \text { years old) residing in the } \\
\text { census tract around the metro }\end{array}$ & 1553 & 1222.4 & 63 & 4454 \\
\hline Passengers & $\begin{array}{l}\text { Number of passengers per annum in millions per station in } \\
\text { logarithmic form }\end{array}$ & 3.68 & 0.82 & 1.79 & 5.54 \\
\hline
\end{tabular}

each of the stations, in order to form a cross-sectional dataset using the station as the unit of analysis $i$ for $t=2010$.

The variables in Table 1 have different units of measurement, they are therefore all standardized, and marginal contributions should be interpreted as variations in standard deviations.

\section{Results}

\section{Temporal Analysis of Crime Inside and Outside Stations}

Figure 2 illustrates the variation in thefts and robberies by hours of the day and day of the week inside and outside the stations. The proportion of thefts that happen inside the station has peaks during the busiest hours ( 6 am to 9 am and $4 \mathrm{pm}$ to $7 \mathrm{pm}$ ), showing the relationship between typical crime opportunities for theft in crowded environments at rush hours in the station. Thefts around the station are concentrated during non-peak hours (between 10 am and $4 \mathrm{pm}$ ). However, for robbery, there is an increasing trend of offences being committed throughout the hours of the day both inside and outside the station. In addition, more robberies seem to take place during non-peak hours inside the station than during the rush hours, when the flow of passengers is less intense.

In terms of week variation (as a 7 days period), thefts in the stations occur mainly on weekdays, with lower incidence on Saturday and Sunday. For robbery, the pattern is more homogeneous throughout the week, but more crime happens during weekends and less on Tuesdays and Wednesdays inside of stations as compared with outside. 

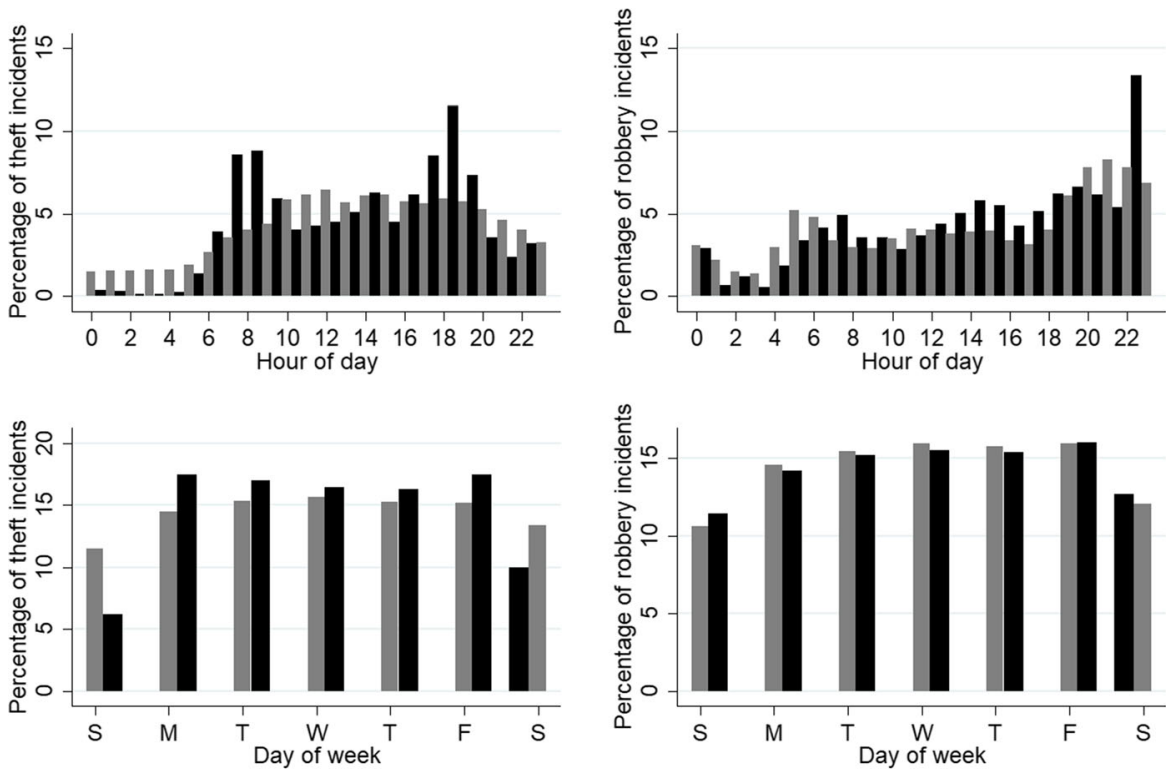

Inside

\section{Around}

Fig. 2 Percentage of thefts and robberies inside and outside stations by hour and day of the week, 2010-2017

In Fig. 2, it is also possible to note that the nature and levels of crimes vary between inside and outside stations. Most of the crimes are recorded in the station: thefts compose of 55\%, while robberies correspond to $14 \%$. Around the station, the proportion of thefts and robberies is $27 \%$ and $55 \%$, respectively.

In addition to the visual analysis provided by Fig. 2, a test of proportion of means was carried out to verify whether the proportions of crimes that occur inside and outside the stations were correlated (Table 2). For all periods considered, there is no temporal correlation between thefts that occur inside and outside the stations. However, in the case of robberies, results show that the proportion of crimes that occur inside the metro during morning peak hours $(06: 00$ 09:59) was correlated with the crime that occurs in the surroundings of the station during late

Table 2 Two-sample test of proportions ( $z$ value displayed) between hours of day, 2010-2017

\begin{tabular}{|c|c|c|c|c|c|c|c|c|c|c|c|}
\hline & & \multicolumn{7}{|l|}{ Theft } & \multicolumn{3}{|c|}{ Robbery } \\
\hline \multirow{6}{*}{ Around } & & Inside & & & & \multirow{6}{*}{ Around } & & & Inside & & \\
\hline & & $1 \mathrm{st}$ & 2 nd & $3 \mathrm{rd}$ & 4th & & & $1 \mathrm{st}$ & 2nd & $3 r d$ & 4 th \\
\hline & $1 \mathrm{st}$ & 44.66 & 39.46 & 57.94 & 41.49 & & $1 \mathrm{st}$ & 11.07 & 11.27 & 10.88 & $0.99^{\text {ns }}$ \\
\hline & $2 \mathrm{nd}$ & 18.02 & 13.92 & 28.88 & 60.80 & & 2nd & 4.04 & 3.87 & 4.20 & 12.67 \\
\hline & $3 \mathrm{rd}$ & 27.72 & 23.29 & 39.54 & 53.73 & & $3 r d$ & 2.91 & 3.09 & 2.73 & 6.40 \\
\hline & 4 th & 6.79 & 3.08 & 16.51 & 68.95 & & 4 th & $0.03^{\mathrm{ns}}$ & $0.21^{\mathrm{ns}}$ & $0.14^{\mathrm{ns}}$ & 9.00 \\
\hline
\end{tabular}

All $z$ values were significant at the $5 \%$ level, with the exception of values overwritten with the term ns. H0, the proportion of crimes that occurred in period $i$ and $j$ outside and inside the station are equal. 1st quartile, 5:0011:59; 2nd quartile, 12:00-16:59; 3rd quartile, 17:00-20:59; 4th quartile, 21:00-04:59 
hours (00:00-05:59). Moreover, the proportion of robberies that occur within the station during afternoon peak hours (17:00-20:59) was not statistically different from the proportion of robberies that occur outside the stations during almost all periods of the day, with the exception of those recorded during morning peak hours.

The same procedure presented in Table 2 was performed for the days of the week, separating weekdays from weekends. Results indicated there was no temporal association between crimes that occur inside and outside the stations (during our 7-day testing period) for these days of the week.

\section{Spatial Analysis of Crime Inside and Outside Stations}

Inner city metro stations concentrate more crimes inside than outside these transport nodes compared with any other part of the city. Crimes that occur inside a station are mainly concentrated in stations geographically close to the central station (Sé station), with about $50 \%$ of thefts and robberies occurring in stations within a distance of $3 \mathrm{~km}$.

Figure 3 shows the accumulated distribution of crimes in relation to the distance from the central region, by kernel density functions. This spatial concentration, in turn, is different for crimes that occur in areas close to the stations (not inside), where, for that same distance $(3 \mathrm{~km})$, only $20 \%$ of thefts and $15 \%$ of robberies occur. Results of the two-sample Kolmogorov-Smirnov test ( $p$ value: 0.0000 ) indicates that these distributions are not statistically similar. This spatial analysis of the relationship between crime that occurs inside or outside is further discussed in the next subsection.
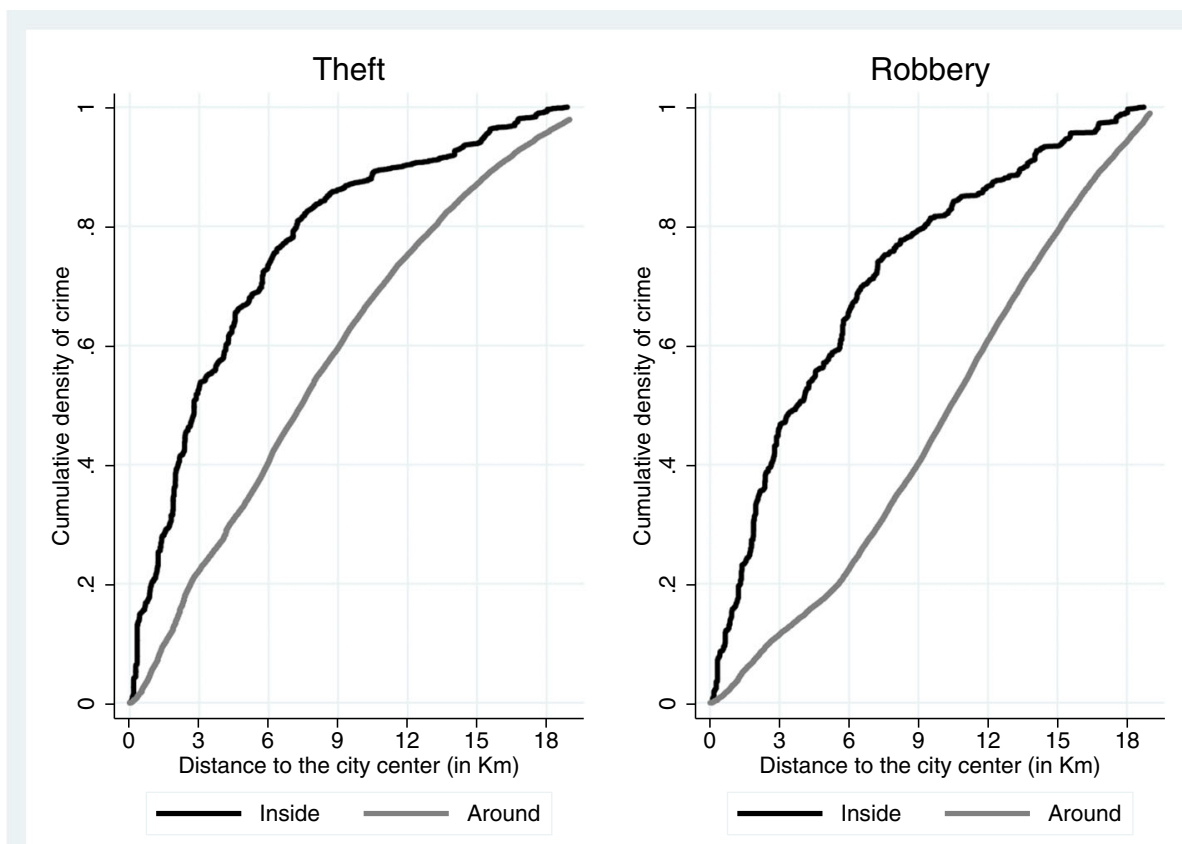

Fig. 3 Thefts and robberies around and inside São Paulo's metro according to the distance to the city centre (Sé station) 
Although findings for São Paulo indicate that there is a concentration of crimes in a few stations, the spatial distribution of thefts and robberies does not follow the same pattern from centre to periphery or between those levels that occur inside and outside the stations for these offences. These results are distinct from those found in the literature (Ceccato et al. 2013; Irvin-Erickson and La Vigne 2015; Newton et al. 2014).

\section{Explaining the Difference in Crime Levels by Stations}

Table 3 summarizes the results of three sets of empirical models for theft and robbery that occurred in the stations. The first set of models takes into account the characteristics of the station only (indicated as 'Station' in Table 3), the second set includes data on land use and crime around the stations (indicated as ' + Landuse' in Table 3 ) and the third set of models includes socio-economic characteristics of the surrounding areas of the stations (indicated as ' + SES' in Table 3). For all models, the alpha overdispersion test is statistically different from zero, which confirms that negative binomial models are more appropriate than the Poisson models, because the conditional variance is greater than the

Table 3 Analysis results that explain thefts and robberies in São Paulo's metro in 2010

\begin{tabular}{|c|c|c|c|c|c|c|}
\hline & \multicolumn{3}{|l|}{ Theft } & \multicolumn{3}{|l|}{ Robbery } \\
\hline & Station & +Landuse & $+\mathrm{SES}$ & Station & +Landuse & $+\mathrm{SES}$ \\
\hline \multirow[t]{2}{*}{ CCTV } & $-0.28^{* * *}$ & $-0.23^{* * *}$ & $-0.20^{* * *}$ & $-0.19^{* * * *}$ & $-0.18^{* * *}$ & $-0.19^{* *}$ \\
\hline & $(0.07)$ & $(0.06)$ & $(0.07)$ & $(0.07)$ & $(0.07)$ & $(0.08)$ \\
\hline \multirow[t]{2}{*}{ Endstation } & $0.14^{* * * *}$ & $0.16^{* * * *}$ & $0.18^{* * *}$ & $0.12^{* * *}$ & $0.14^{* * * *}$ & $0.12^{* * *}$ \\
\hline & $(0.04)$ & $(0.04)$ & $(0.04)$ & $(0.05)$ & $(0.05)$ & $(0.05)$ \\
\hline \multirow[t]{2}{*}{ Transition station } & $0.18^{* * * *}$ & -0.05 & -0.03 & -0.00 & 0.01 & 0.03 \\
\hline & $(0.06)$ & $(0.06)$ & $(0.05)$ & $(0.06)$ & $(0.07)$ & $(0.06)$ \\
\hline \multirow[t]{2}{*}{ Centralstation } & $0.15^{* * * *}$ & -0.06 & -0.04 & $-0.11^{*}$ & 0.04 & 0.01 \\
\hline & $(0.04)$ & $(0.05)$ & $(0.04)$ & $(0.07)$ & $(0.08)$ & $(0.07)$ \\
\hline \multirow[t]{2}{*}{ Crimearound } & & $0.42^{* * * *}$ & $0.36^{* * *}$ & & $0.37^{* * * * *}$ & $0.36^{* * * *}$ \\
\hline & & $(0.12)$ & $(0.11)$ & & $(0.05)$ & $(0.05)$ \\
\hline \multirow[t]{2}{*}{ Green area } & & $0.13^{* *}$ & 0.08 & & -0.02 & -0.03 \\
\hline & & $(0.06)$ & $(0.07)$ & & $(0.05)$ & $(0.06)$ \\
\hline \multirow[t]{2}{*}{ Parking lot } & & 0.04 & 0.02 & & 0.02 & 0.04 \\
\hline & & $(0.05)$ & $(0.05)$ & & $(0.04)$ & $(0.04)$ \\
\hline \multirow[t]{2}{*}{ Bus stops } & & $0.18^{* * * *}$ & $0.16^{* * * *}$ & & $0.15^{* * * * *}$ & $0.15^{* * * *}$ \\
\hline & & $(0.06)$ & $(0.05)$ & & $(0.04)$ & $(0.04)$ \\
\hline \multirow[t]{2}{*}{ Commercial } & & $0.17^{* * * *}$ & $0.18^{* * * *}$ & & $0.22^{* * * *}$ & $0.23^{* * * *}$ \\
\hline & & $(0.04)$ & $(0.04)$ & & $(0.05)$ & $(0.06)$ \\
\hline \multirow[t]{2}{*}{ Schools } & & 0.02 & 0.03 & & -0.00 & 0.00 \\
\hline & & $(0.04)$ & $(0.04)$ & & $(0.04)$ & $(0.04)$ \\
\hline \multirow[t]{2}{*}{ Income } & & & $-0.10^{* *}$ & & & $-0.10^{*}$ \\
\hline & & & $(0.04)$ & & & $(0.05)$ \\
\hline \multirow[t]{2}{*}{ Young men } & & & 0.33 & & & -0.16 \\
\hline & & & $(0.23)$ & & & $(0.19)$ \\
\hline \multirow[t]{2}{*}{ Passengers } & $0.11^{*}$ & 0.07 & -0.19 & $-0.09^{*}$ & -0.04 & 0.16 \\
\hline & $(0.06)$ & $(0.04)$ & $(0.22)$ & $(0.05)$ & $(0.04)$ & $(0.19)$ \\
\hline \multirow[t]{2}{*}{ Constant } & $5.01^{* * * *}$ & $4.91^{* * * *}$ & $4.91^{* * * *}$ & $8.96^{* * * *}$ & $8.92^{* * * * *}$ & $8.92^{* * * *}$ \\
\hline & $(0.06)$ & $(0.04)$ & $(0.04)$ & $(0.05)$ & $(0.04)$ & $(0.04)$ \\
\hline AIC & 1679 & 1614 & 1610 & 2769 & 2737 & 2737 \\
\hline $\mathrm{BIC}$ & 1699 & 1652 & 1655 & 2790 & 2775 & 2782 \\
\hline
\end{tabular}

Standardized regression coefficients; Robust standard errors in parentheses; ${ }^{*} p<0.10,{ }^{* *} p<0.05,{ }^{* * *} p<0.01$ 
conditional average for the distribution of crimes within the station (for more details, see Rabe-Hesketh and Everitt 2003).

The 'Crimearound' variable captures whether levels of robbery and theft that occur around the station affect the number of thefts and robberies recorded inside the station. Although bivariate tests in 'Temporal Analysis of Crime Inside and Outside Stations' section indicated statistical independence between these two distributions, modelling results show the opposite. After controlling for internal and other external characteristics of the station, modelling results indicated that levels of crime that happens around the station does have an impact on theft and robbery inside the station. Compared with other variables, the effect of surroundings is small but significant.

CCTV is the variable that remains significant for all models, indicating a decreasing effect on crime levels for theft and robbery, both when controlling for differences in land use and socio-economic conditions of the resident population.

Although crime tends to be highly concentrated in inner city stations (Fig. 3), modelling results show that being an end station makes a station more vulnerable to crime than any other type of station (transitional or central), because those stations are located in peripheral areas in the city of São Paulo, where is possible to observe a higher level of social disorganization (i.e. poverty, favelas and criminal organizations) compared with other stations. Thus, although the spatial analysis presented in Fig. 3 indicates a higher incidence of crimes in the areas close to the central station, this effect disappears when aspects of land use and socio-economic characteristics are controlled for.

Attention should be drawn to the significant effect that different types of land use close to the metro have on thefts and robberies in the station. For robbery in particular, bus stops and commercial areas make the station more criminogenic. These findings suggest an interaction between the internal and external environments of the stations and surrounding areas. This interaction is most likely determined by the dynamics of people's routine activity on the way from and to these transport nodes. These findings are also indicative of a process of crime transmission/diffusion between the criminogenic conditions promoted by bus stops and commercial areas and those found in the station.

\section{Discussion of the Results}

The aim of this study was to investigate the nature and space-temporal dynamics of theft and robbery in São Paulo's metro stations and their immediate surrounding areas. Thefts and robberies show distinct temporal and spatial patterns of occurrence, confirming the first hypothesis. Thefts are more common inside the stations, while robberies are more common outside, in the surrounding areas. While thefts take place often during peak hours, robbery tends to happen during off-peak hours and more often outside the stations, in places that allow some degree of anonymity to the offender.

Thefts tend to be a weekday phenomenon, while robberies show a more homogeneous pattern over the week, albeit occurring more frequently on weekends. This difference in the nature of crimes may suggest that criminals who steal from travellers inside the stations may not be the same as those who rob transients outside. However, if they are the same criminals, they are versatile in their modus operandi and adapt to these different situational conditions of transit environments. Since thefts and robberies have different modus operandi, these results indicate there might be a degree of specialization in criminal activity defined by the types of 
environment. This hypothesis of specialization was suggested by Newton et al. (2014) when they verified differences between thefts against the person and other types of crime for the London Underground.

Our confirmatory analysis shows that the variable that indicates crime around the stations was significant for both theft and robbery. Although the observed effect is small, it is statistically significant and indicates that there is an interaction between the criminogenic conditions in the stations and those thefts and robberies that took place in the environments around the stations, and most likely vice versa. This interaction effect between what happens inside and outside the stations is not unique to São Paulo. Newton et al. (2014) found, for example, that crimes inside and outside London Underground stations were positively correlated throughout the hours of the day, with a few exceptions during off-peak hours. Bowers (2014:389) explored the nature of the relationship between internal crimes (those that happen within facilities) and external crimes (those occurring outside but near facilities) in risky facilities and identified two types of risky facilities: crime radiators and crime absorbers. Crime radiators 'cause crime in the immediate environment as well as internally', while crime absorbers attract crime internally from their surroundings that are highly criminogenic. Previous literature has shown examples of both processes. For example, Brantingham et al. (1991) showed examples of crime radiators in Vancouver where public transit fed crime in the immediate areas. Similarly, Block and Block (2000) characterized street robbery in the environs of rapid transit stations in the Bronx and Chicago. See also Belanger (1999), Smith and Cornish (2006) and Tsai et al. (2011) for more evidence of crime transmission.

For theft and robbery-but for robbery in particular-our modelling results show an indirect indication of the direction of the transmission: from the surrounding areas of the station into the station. Findings showed that bus stops and commercial areas (acting as crime radiators) in a station's surrounding areas increased robbery levels inside the metro station (acting as a crime absorber). Thus, we can conclude that metro stations that have a surrounding area with these particular land uses (which attract crime in the immediate surroundings of the stations) are bound to also absorb crime into the station, thus constituting a crime absorber. For theft, the direction of the transmission is less clear than for robbery, because theft tends to be concentrated inside metro stations and is not as affected by theft levels in the surrounding areas as robbery is. This means that whether a station is a crime absorber or a radiator depends on the type of crime (as illustrated in this study) and the types of station surroundings (whether they contain crime radiators and crime absorbers and/or where socially disorganized neighbourhoods lead to poor social control and, in turn, crime).

However, a test to identify the direction of this crime transmission has not been performed in this study, as this would require a range of data that were not available. For a causal relationship, more appropriate methods in combination with other types of data would be necessary. They would include, for example, the implementation of instrumental variables and panel data in time series analysis. Then, the results of this analysis should be interpreted not as a causal evidence but rather as conditional correlations.

For thefts and robberies, despite the fact that inner city metro stations concentrate lots of crimes, we see that when land use and socio-economic conditions are controlled for, end stations experience more crime than central stations, but this effect disappears for thefts. Previous research on stations in São Paulo shows that thefts and robberies (and total crimes) 
are found located in inner city areas but also in smaller stations and in relatively wealthier neighbourhoods (Ceccato and Paz 2017). For thefts and robberies in metro stations, poorer contexts tend to boost crime levels in the stations, but the proportion of young males is not a significant indicator of the variation of these crimes. As for the internal characteristics of the stations, the presence of CCTV is shown to be highly significant in the reduction of both thefts and robberies. The effectiveness of CCTVs in reducing crime at the stations is supported by the literature (e.g. Pricks 2015), but mixed evidence is also found in previous studies in relation to transportation nodes (Ceccato et al. 2013).

The effect of bus stops and commercial areas also indicated that the stations' surroundings are important to explain the variation of levels of thefts and robberies in São Paulo metro. Bus stops near metro stations can facilitate the mobility and access of metro stations for potential offenders; they can also provide targets for pickpocketing, for instance, while commercial areas can generate opportunities related to potential victims carrying valuable goods.

\section{Conclusions and Recommendations}

This article makes a contribution to the way police recorded crime data can be aggregated in geographically detailed units (metro stations and surrounding areas) and further analysed using GIS. This framework enabled us to assess crime at São Paulo's metro stations in relation to daily and weekly variations. Visual inspection combined with rigorous statistical analysis, including binomial regression models, were useful to assess temporal and spatial patterns of crime using metro stations as reference. The analysis of crimes in these risky facilities provides us with snapshots of what happens in the overall city in terms of crime risk over time and space using traditional statistical data aggregated by stations and neighbourhoods (point and polygon units). We suggest that the analysis of what happens inside and outside metro stations has the capacity to reflect the dynamics of the city as a whole. One of the advantages of this methodology is that it does not require individual-based data to produce an indication of crime risk in the city, as in most current studies based on offenders' movement patterns. This is because metro stations become a catalyst hub for specific but relevant temporal and spatial variations of crime beyond these transit environments and can therefore be useful for targeted planning purposes.

Theft happens more often inside the station, while robbery happens outside, with clear signs of interactions between these environments for robbery. However, whether a station is a crime absorber or a crime radiator depends on the crime type. Findings indicate that bus stops and commercial areas (acting as crime radiators) in a station's surrounding areas increase robbery levels inside the metro station (acting as a crime absorber). For theft, the direction of the transmission is not clear and may be non-existent, because thefts are typical offences that take place inside the metro stations.

These results have implications for crime prevention policy in terms of facility placement and management. As previously suggested by Moreira and Ceccato (2020), since the characteristics of a station's immediate areas have an impact on the incidence of robbery within the station, a multi-pronged approach to tackle robbery is necessary. Strategies that link public authorities, businesses, residents, nongovernmental organizations and the metro security staff in a joint collaborative safety initiative are highly desirable. 
Although crime is often highly concentrated in a few inner city and end stations, it varies depending on location and time. If we are aware of these spatiotemporal patterns of regularities, then we have taken the first step towards defining more precisely targeted resources to tackle metro stations that are crime-ridden and towards formulating preventive strategies (Hirschfield et al. 1995), as done in this study. Safety interventions should avoid one-size-fits-all solutions for inner city stations and end stations, because the dynamics of inner city metro stations are bound to be different from those of stations in the outskirts of the city, with end stations being connected to buses and other modes of public transportation as well as parking and rides. Such differences in context matter greatly in situational crime prevention.

One limitation of this study is that criminal records tend to be unequally underreported 'spatially' in São Paulo. Some metro stations have better mechanisms for reporting crime than others do, such as the presence of Police departments near stations, as in the case of Sé station. This may change the spatial patterns discussed in this study, although it is difficult to get around this problem. This limitation is faced by other studies analysing property crimes recorded by the police (e.g. Solymosi and Bowers 2018). Another limitation is that the results provided by the empirical analysis of this study should be interpreted as conditional correlations and not as causal effects, since it was not possible to control all factors that affect property crimes in metro stations such as on-street population, number of security staff and other variables. Although our findings show indications of a process of crime transmission/diffusion between the inside and outside of stations, note that a test to identify the direction of this crime transmission has not been performed in this study, which we recommend in future studies.

Despite these limitations, this study shows the advantages of being crime specific, time specific and location specific (Clarke 1995) when we assess crime at transport nodes. The study also illustrates the potential of using official crime data at metro stations to illustrate the city dynamics that go beyond their locality and surrounding areas - which can be highly relevant for crime prevention.

Future research could investigate in more detail the nature of metro stations as a risky facility and, in particular, as a crime attractor, generator, radiator and/or absorber. Five questions are of notable interest for further research: (1) What is the direction of impact, which risky facilities are crime radiators or crime absorbers and when? (2) Does the size and location of the station affect the nature of a station as crime attractor, generator, radiator and/or absorber? (3) Which land use features and/or demographic and socioeconomic factors most affect a risky facility? (4) How can current environmental criminology theory (e.g. principles of routine activity, point pattern theory and social disorganization) be used to help interpret the mechanisms and dynamics linking metro stations and their surrounding areas? (5) How can safety interventions and urban planning best incorporate the notions of crime attractor, generator, radiator and/or absorber to tackle safety problems in risky facilities?

Acknowledgements The research for this article was undertaken while Gustavo Moreira was a visiting researcher at KTH Royal Institute of Technology, Stockholm, Sweden. The authors would also like to express their thanks to those organizations providing the data used in this analysis, in particular the Public Security Secretary of São Paulo.

Funding information Open access funding provided by KTH Royal Institute of Technology. 


\section{Appendix}

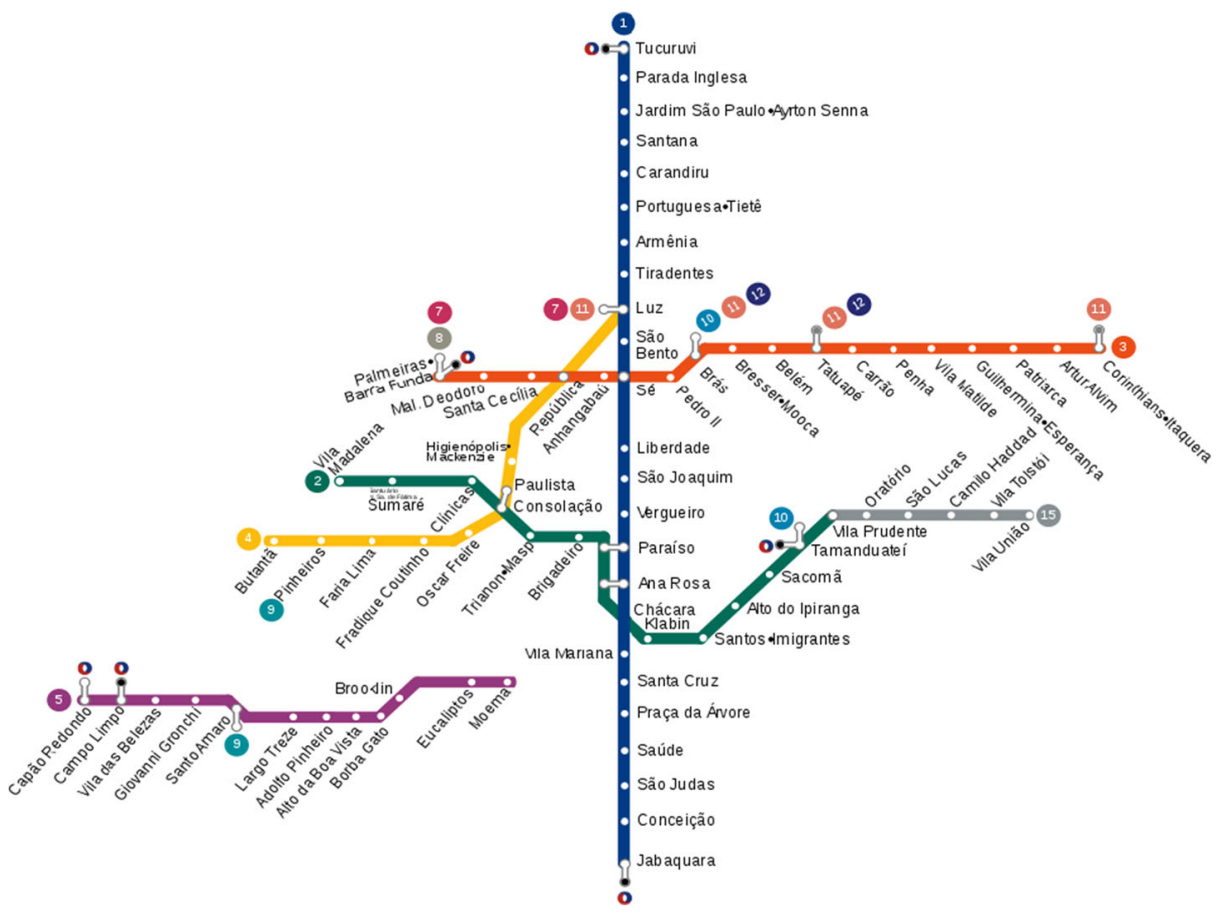

Fig. 4 São Paulo’s metro system, 2018 


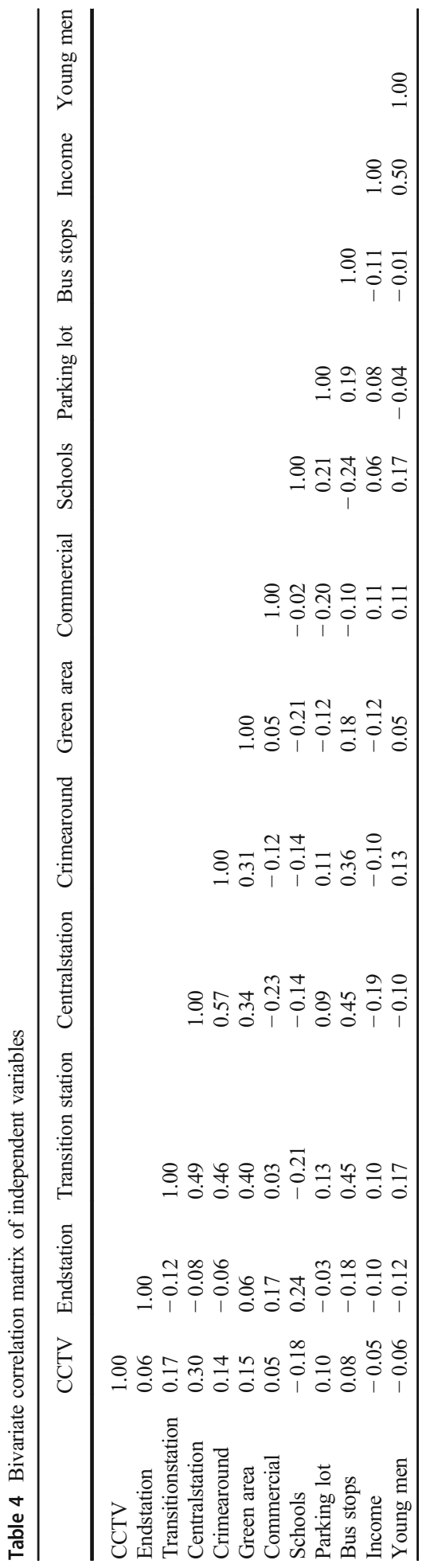


Open Access This article is licensed under a Creative Commons Attribution 4.0 International License, which permits use, sharing, adaptation, distribution and reproduction in any medium or format, as long as you give appropriate credit to the original author(s) and the source, provide a link to the Creative Commons licence, and indicate if changes were made. The images or other third party material in this article are included in the article's Creative Commons licence, unless indicated otherwise in a credit line to the material. If material is not included in the article's Creative Commons licence and your intended use is not permitted by statutory regulation or exceeds the permitted use, you will need to obtain permission directly from the copyright holder. To view a copy of this licence, visit http://creativecommons.org/licenses/by/4.0/.

\section{References}

Becker, G. S. (1968). Crime and punishment: An economic approach, In the economic dimensions of crime (pp. 13-68). London: Palgrave Macmillan.

Belanger, M. (1999). Crime mobility and public transport: The case of the New York City subway. Doctoral dissertation: Rutgers University, The State University of New Jersey.

Block, R., \& Davis, S. (1996). The environs of rapid transit stations: A focus for street crime or just another risky crime? Preventing mass transit crime (pp. 237-257). Monsey, NY: Criminal Justice press.

Block, R. \& Block, C. R. (1999). Risky places: A comparison of the environs of rapid transit stations in Chicago and the Bronx. In Mollenkopf, J. (ed.), Analyzing Crime Patterns: Frontiers of Practice, sage publishing: Beverly Hills, CA.

Block, R. L., \& Block, C. R. (2000). The Bronx and Chicago: Street robbery in the environs of rapid transit stations. In J. Nollenkopf (Ed.), Analyzing crime patterns: Frontiers in practice (pp. 137-152). London: Sage.

Bowers, K. (2014). Risky facilities: Crime radiators or crime absorbers? A comparison of internal and external levels of theft. Journal of Quantitative Criminology, 30(3), 389-414.

Brantingham, P. J., Brantingham, P. L., \& Wong, P. S. (1991). How public transit feeds private crime: Notes on the Vancouver 'sky train' experience. Security Journal, 2, 91-94.

Brantingham, P. L., \& Brantingham, P. J. (1993). Nodes, paths and edges: Considerations on the complexity of crime and the physical environment. Journal of Environmental Psychology, 13(1), 3-28.

Brantingham, P., \& Brantingham, P. (1995). Criminality of place. European Journal on Criminal Policy and Research, 3(3), 5-26.

Burrell, A. (2007). Violence on and around public transport. London: UCL Jill Dando Institute, University College London.

Bursik Jr., R. J., \& Webb, J. (1982). Community change and patterns of delinquency. American Journal of Sociology, 88(1), $24-42$.

Cameron, A. C., \& Trivedi, P. K. (2001). Essentials of count data regression. A companion to theoretical econometrics, 331.

Cameron, A. C., \& Trivedi, P. K. (2005). Microeconometrics: Methods and applications. Cambridge university press.

Ceccato, V. (2005). Homicide in São Paulo, Brazil: Assessing spatial-temporal and weather variations. Journal of Environmental Psychology, 25(3), 307-321.

Ceccato, V., Haining, R., \& Kahn, T. (2007). The geography of homicide in São Paulo, Brazil. Environment and Planning A, 39(7), 1632-1653.

Ceccato, V. (2013). Moving safely: Crime and perceived safety in Stockholm's subway stations. Lexington books.

Ceccato, V., Uittenbogaard, A., \& Bamzar, R. (2013). Security in Stockholm's underground stations: The importance of environmental attributes and context. Security Journal, 26(1), 33-59.

Ceccato, V., \& Uittenbogaard, A. C. (2014). Space-time dynamics of crime in transport nodes. Annals of the Association of American Geographers, 104(1), 131-150.

Ceccato, V., Cats, O., \& Wang, Q. (2015). The geography of pickpocketing at bus stops: An analysis of grid cells. In V. Ceccato \& A. Newton (Eds.), Safety and security in transit environments: An interdisciplinary approach (pp. 76-98). London: Palgrave Macmillan UK.

Ceccato, V., \& Paz, Y. (2017). Crime in São Paulo's metro system: Sexual crimes against women. Crime Prevention and Community Safety, 19(3-4), 211-226.

Ceccato, V. (2017). Does poverty cause violence? The Wiley Handbook of Violence and Aggression, 1-13.

Ceccato, V. (2018). Crime in transit environments: Lessons from Stockholm (Sweden) and São Paulo (Brazil) metro systems : 交通环境犯罪: 从瑞典斯德哥尔摩和巴西圣保罗地铁系统的经验总结. Landscape Architecture, 7. 
Ceccato, V., \& Loukaitou-Sideris, A. (2020). Transit crime and sexual violence in cities: International Evidence and Prevention. London: Routledge.

Clarke, R. V. (1995). Situational Crime Prevention. Crime and Justice, 19, 91-150.

Clarke, R. V. G., \& Eck, J. E. (2007). Understanding risky facilities. Washington, DC: US Department of Justice, Office of Community Oriented Policing Services.

Cohen, L. E., \& Felson, M. (1979). Social change and crime rate trends: A routine activity approach. American Sociological Review, 588-608.

Cozens, P., Neale, R., Whitaker, J., \& Hillier, D. (2003). Making crime and the fear of crime at railway stations A case study in South Wales (UK). International Journal of Transport Management, 1, 121-132.

d'Arbois de Jubainville, H., \& Vanier, C. (2017). Women's avoidance behaviours in public transport in the Ile-deFrance region. Crime Prevention and Community Safety, 19(3-4), 183-198.

Felson, M., \& Poulsen, E. (2003). Simple indicators of crime by time of day. International Journal of Forecasting, 19(4), 595-601.

Greene, W. H. (2003). Econometric analysis. Pearson Education India.

Hilbe, J. M. (2011). Negative binomial regression. Cambridge University Press.

Hirschfield, A., Bowers, K. J., \& Brown, P. J. B. (1995). Exploring relations between crime and disadvantage on Merseyside. European Journal on Criminal Policy and Research, 3(3), 93-112.

Hirschfield, A., \& Bowers, K. J. (1997). The effect of social cohesion on levels of recorded crime in disadvantaged areas. Urban Studies, 34, 1275-1295.

Irvin-Erickson, Y., \& La Vigne, N. (2015). A spatio-temporal analysis of crime at Washington, DC metro rail: Stations' crime-generating and crime-attracting characteristics as transportation nodes and places. Crime Science, 4(1), 14.

Kornhauser, R. R. (1978). Social sources of delinquency: An appraisal of analytic models.

La Vigne, N. G. (1996). Safe transport: Security by design on the Washington metro. Preventing mass transit crime, 6, 163-197.

La Vigne, N. G. (1997). Visibility and vigilance: Metro's situational approach to preventing subway crime (p. 20). Washington, DC: US Department of Justice, Office of Justice Programs, National Institute of Justice.

Levine, N., \& Wachs, M. (1986). Bus crime in Los Angeles: II - victims and public impact. Transportation Research, 20(4), 285-293.

Loukaitou-Sideris, A., Liggett, R., \& Iseki, H. (2002). The geography of transit crime: Documentation and evaluation of crime incidence on and around the green line stations in Los Angeles. Journal of Planning Education and Research, 22(2), 135-151.

Loukaitou-Sideris, A. (2011). Safe on the move: The importance of the built environment, In: The urban fabric of crime and fear (pp. 85-110). Dordrecht: Springer.

Magnusson, M. (2020) Mapping open drug scenes (ODS). In: Crime and fear in public places. V. Ceccato \& M. K. Nalla (Ed.), Routledge.

Mazeika, D. M., \& Kumar, S. (2017). Do crime hot spots exist in developing countries? Evidence from India. Journal of Quantitative Criminology, 33(1), 45-61.

Metro (2019). User flow statistics. Available at: https://ransparencia.metrosp.com.br/dataset/demanda. Accessed 13 Sept 2019.

Moreira, G. C., \& Ceccato, V. A. (2020). Gendered mobility and violence in the São Paulo metro. Brazil. Urban Studies. https://doi.org/10.1177/0042098019885552.

Myhre, M., \& Rosso, F. (1996). Designing for security in meteor: A projected new metro line in Paris. Preventing mass transit crime, 199-216.

Natarajan, M. (2016). Rapid assessment of "eve teasing" (sexual harassment) of young women during the commute to college in India. Crime Science, 5(1), 1-11.

Newton, A. D. (2004). Crime on public transport: 'Static'and'Non-Static'(moving) crime events. Western Criminology Review, 5(3).

Newton, A. D., \& Bowers, K. J. (2007). The geography of bus shelter damage: The influence of crime, neighbourhood characteristics and land-use. Internet Journal of Criminology.

Newton, A. D., Partridge, H., \& Gill, A. (2014). Above and below: Measuring crime risk in and around underground mass transit systems. Crime Science, 3(1), 1.

Newton, A., Partridge, H., \& Gill, A. (2015). In and around: Identifying predictors of theft within and near to major mass underground transit systems. In: Safety and Security in Transit Environments (pp. 99-115). Palgrave Macmillan, London.

Osgood, D. W. (2000). Poisson-based regression analysis of aggregate crime rates. Journal of Quantitative Criminology, 16(1), 21-43.

Piza, E., \& Kennedy, D. (2013). Transit stops, robbery, and routine activities: Examining street robbery in the Newark, NJ subway environment. 
Priks, M. (2015). The effects of surveillance cameras on crime: Evidence from the Stockholm subway. The Economic Journal, 125(588).

Rabe-Hesketh, S., \& Everitt, B. (2003). Handbook of statistical analyses using Stata. CRC Press.

Ratcliffe, J. (2010). Crime mapping: Spatial and temporal challenges. In: Handbook of quantitative criminology (pp. 5-24). Springer, New York, NY.

Rosenfeld, R., Baumer, E. P., \& Messner, S. F. (2001). Social capital and homicide. Social Forces, 80(1), 283310.

Sampson, R. J., Raudenbush, S. W., \& Earls, F. (1997). Neighborhoods and violent crime: A multilevel study of collective efficacy. Science, 277(5328), 918-924.

Shaw, C. R., \& McKay, H. D. (1942). Juvenile delinquency and urban areas. Chicago: University of Chicago Press.

Shellow, R., Romualdi, J. P., \& Bartel, E. W. (1974). Crime in rapid transit systems: An analysis and a recommended security and surveillance system. Transportation Research Record, 487, 34-45.

Shibata S., Hanyu K., Hata T.D., Yamaoka Y. (2015) Perception of disorder and crime, and responses to them in Japanese 'mega' railway stations. In: Ceccato V., Newton A. (eds) Safety and security in transit environments. Crime Prevention and Security Management. Palgrave Macmillan, London.

Smith, M. J., \& Clarke, R. V. (2000). Crime and public transport. Crime and Justice, 27, 169-233.

Smith, M. J., \& Cornish, D. B. (2006). Secure and Tranquil Travel - Preventing Crime and Disorder on Public Transport. UCL Jill Dando Institute of Crime Science. London: University of London.

Solymosi, R., \& Bowers, K. (2018). The role of innovative data collection methods in advancing criminological understanding. The Oxford Handbook of Environmental Criminology, 210, 210-237.

Thrasher, E., \& Schnell, J. (1974). Scope of crime and vandalism on urban transit systems. Transportation Research Record, 487, 34-45.

Tsai, L. C-F., Zhang, Y. \& Hoover, L.T. (2011). Distribution of street robberies in relation to bus stops in Houston. Paper presented 68th annual meeting of the American Association of Criminology, Washington, D.C.

Uittenbogaard, A., \& Ceccato, V. (2015). Temporal and spatial patterns of suicides in Stockholm's subway stations. Accident Analysis \& Prevention, 81, 96-106.

UN - United Nations-Habitat (2018). Activities of the United Nations human settlements programme draft United Nations system-wide guidelines on safer cities and human settlement. United Nations-habitat, Safe cities programe, Nairobi, $13 \mathrm{p}$.

Vandeviver, C., Bernasco, W., \& Van Daele, S. (2019). Do sports stadiums generate crime on days without matches? A natural experiment on the delayed exploitation of criminal opportunities. Security Journal, 32(1), 1-19.

Webb, B., \& Laycock, G. (1992). Reducing crime on the London underground. Crime prevention unit paper, 30.

Publisher's Note Springer Nature remains neutral with regard to jurisdictional claims in published maps and institutional affiliations. 